\title{
Assessment of respite needs for carers of persons with severe mental illness
}

\author{
Katy Malcolm, Paul Rowlands and Heather Inch
}

Resplite needs for carers of persons with severe mental iliness were assessed using a semi-structured inverview. Very few carers were currently using respite facillites. The need for resplite was widespread, although largely unmet. Carers shared clear and definite ideas conceming the layout of a good resplite senvice.

The burdens of caring for a mentally ill relative or friend are now recognised (Fadden et al, 1987; Kuipers, 1992), and can range from the demanding and repetitive nature of care giving tasks, through to financial difficulties and the restrictions placed on carers' 'social' and leisure activities (Kuipers, 1993).

Respite care is offered to care-givers as a step towards trying to relieve some of this burden. Twigg et al (1990) point out that respite care can be offered in many ways, including day care, respite care in institutions, family placement schemes and sitter or other home relief services. With the programme of closure of long-term facilities for the mentally ill, at least one form of respite care, that of institutionally-based respite, will be lost.

It is known that the carers of the mentally ill cope with very difficult behaviour often without complaint (Creer et al, 1982), but when studies are aimed at identifying requirements for items of care, including respite, unmet need has been demonstrated (MacCarthy et al, 1989).

There are few studies investigating respite care for the mentally ill. However, positive benefits from respite schemes have been shown by some investigators (Geiser et al, 1988; Turkington et al, 1991).

In view of the impending loss of institutionallybased respite care and the lack of knowledge of the types of respite required by carers and clients with mental illness, we proposed to establish the use of existing respite facilities in our area, how these facilities were obtained, and the size and nature of any unmet need for respite facilities.

\section{The study}

In order to establish who was already using respite facilities, we screened groups of carers and sufferers from the following sources: community rehabilitation team (CRT) database; the computerised mental health data collection system Psymon for all psychiatric in-patients over the year February 1995 to February 1996; local authority city-wide resource panel database for unmet needs in those with mental disorder; local authority home finding unit database for adult fostering services; local carers via an advertisement in the local carers' newspaper.

We then interviewed all persons currently using respite and all cooperating respondents.

\section{Findings}

The trawl of Psymon revealed no respite admissions, although some staff reported that there were a few respite admissions, "through the back door' that had been coded as ordinary in-patient stays.

Screening the local authority home finding unit revealed no respite placements for severe mental illness, although schemes did exist for placing patients with learning disabilities or elderly persons with cognitive impairment. Screening the local authority resource panel revealed one referral for respite which was provided out of the city.

Screening the CRT database showed no clients receiving respite. The database revealed 324 carers, looking after clients who had had at least a year of contact with psychiatric services. The total of persons agreeing to interview as 91 , with 87 coming from the CRT database and three via the carers' newsletter.

\section{The carers}

The majority of carers were parents (69\%) or spouses $(28 \%)$ of the user, with siblings $(3 \%)$ making up the remainder. They had spent on 
average 21 years (range 2 to 30 years) caring for their user.

\section{Support}

The carers were usually shouldering their burden alone, without help from other family members or friends. Statutory agencies provided support in all cases, but the range of provision varied widely in quality and quantity.

\section{Time spent caring}

Carers spent an average of 53 hours a week (range 18-95 hours per week) in caring, with most of the time being spent in face-to-face contact with their user.

Duties involved in caring

All carers took on extra domestic duties such as cooking, cleaning and shopping. Many had to assist or motivate their relative in activities of daily living such as dressing and washing, which several commented on as being embarrassing for both themselves and the relative or spouse. Forty-four (48\%) took their relative/spouse out on trips, 'to get out of the house' and a similar number $46(51 \%)$ administered or supervised the taking of medication.

\section{Nature of unmet need for respite}

Eighteen carers said they did not need respite, and various reasons were given for this. Some had given up hoping for help and were now resigned to their caring tasks. One parent said, 'Even if they did give us a break in a normal environment, we wouldn't know what to do. We have been reprogrammed as carers now. We are doing a job, but we don't get paid and we don't get holidays'. Others felt ambivalent about respite; they admitted they sometimes felt desperate about their burden, yet at the same time were afraid that using respite would mean that they would lose their role as main care giver, with the result that professionals would take over decisions regarding the way in which their relative was treated.

Seventy-three carers said they wished they could access respite services, with all 73 preferring facilities to be provided at a site other than their own home. Ninety-five per cent said that respite services should not be in a hospital, with several carers commenting that their relative would definitely refuse any hospitalbased service. Hospitals were seen as places for admission for treatment, and often as places to be avoided by both the user and the carer. Hostels were cited as an alternative by $82 \%$ as were hotels (5\%), staffed group homes (74\%), and individual flats/bedsits (37\%).

Mention was frequently made of the importance of pleasant tranquil surroundings (e.g. rural or coastal settings) and the need for space, quiet and the opportunity for activities such as sport, crafts and trips out. All 73 carers said that someone to talk to would be especially important.

Most carers (93\%) thought that respite facilities should be staffed by qualified workers and (92\%) emphasised the importance of provision of staff at night. Many $(81 \%)$ also stressed the importance of having staff familiar to the users to improve continuity of care.

Day care respite was specifically mentioned by $63 \%$ as being a particular need, although only roughly a third (34\%) were receiving day care in either centres (12\%) or hospitals $(22 \%)$.

\section{Comment}

It appears that carers continue to face heavy duties of care. Although the need for respite was widespread, it was largely unmet. Despite this, planning for a respite service is often minimal or non-existent.

Many carers shared clear and definite ideas concerning the layout of the good respite service, which would be usefully adopted to help remedy the gap in service provision. In our own area, partly as a consequence of the issues raised by this survey, four respite beds are to be purchased in statutory and non-statutory hostels by the local authority.

\section{References}

Creer, C., Sturt, E. \& Wykes, T. (1982) The role of relatives. Psychological Medicine, 12 (Monograph suppl. 2), 29 39.

FADDEN, G., BEbBington, P. \& KuIPERs, I. (1987) The burden of care: the impact of functional psychiatric lliness on the patient's family. British Joumal of Psychiatry 160. 285-292.

GeISER, R., Hoche, L. \& ING, J. (1988) Respite care for mentally ill patients and their families. Hospital and Community Psychiatry, 39. 291-295.

KUIPERS, L. (1992) Meeting the needs of relatives. In Measuring Mental Health Needs (eds G. Thornicroft. C. Brewin \& J. Wing). London: Gaskell.

- (1993) Family burden in schizophrenia: Implications for services. Social Psychiatry and Psychiatric Epidemiology. 28, 207-210.

MACCARTHY, B., LESAGE, A.. BREWIN, C., et al (1989) Needs for care among the relatives of long term users of day care. Psychological Medicine, 19, 725-736.

TURKINGTON, D., KINGDON, D. \& MALCOLM, K. (1991) The use of an unstaffed flat for crisis intervention and rehabilitation. Psychiatric Bulletin, 16, 13-14

Twigg, J., AtKIN, K. \& PERrING, C. (1990) Carers and Services: A Review of Research Social Policy Research Unit. London: HMSO.

*Katy Malcolm, Consultant Psychiatrist, Paul Rowlands, Senior Registrar in Psychiatry, Forest Lodge, Sheffield S3O 3JW, and Heather Inch, Senior Registrar in Psychiatry. The Yews Day Hospital, Worral Road, Sheffield S30 3AU

*Correspondence 